\title{
Respiratory Health Problems Among Endoscopy Nurses Exposed to Glutaraldehyde in Zagazig University Hospitals, Egypt
}

\author{
Sarah Abdelhalim Bolbol ", Enjy Ahmad Khorshed, Naema El-Lithy Soliman, \\ Mohammed Magdy Nassef \\ Department of Community, Environmental and Occupational Medicine, Faculty of Medicine, Zagazig University, Zagazig, Egypt
}

Email address:

sar_bo@yahoo.com (S. A. Bolbol)

${ }^{*}$ Corresponding author

\section{To cite this article:}

Sarah Abdelhalim Bolbol, Enjy Ahmad Khorshed, Naema El-Lithy Soliman, Mohammed Magdy Nassef. Respiratory Health Problems Among Endoscopy Nurses Exposed to Glutaraldehyde in Zagazig University Hospitals, Egypt. Science Journal of Public Health. Vol. 4, No. 6, 2016, pp. 451-457. doi: 10.11648/j.sjph.20160406.16

Received: September 18, 2016; Accepted: September 27, 2016; Published: October 18, 2016

\begin{abstract}
Introduction: Glutaraldehyde is still used for sterilization of endoscopes in Egypt and known to be associated with many respiratory problems, so this study aims to establish control program guidelines to promote the respiratory health of endoscopy nurses in Zagazig University Hospitals with the objectives to assess the frequency of respiratory health problems among endoscopy nurses and to identify associated occupational and personal risk factors. Methods: A comparative crosssectional study carried on 42 endoscopy nurses exposed to glutaraldehyde compared to non-exposed 84 nurses working at outpatient clinics. All nurses were subjected to a questionnaire (socio-demographic and occupational characteristics, chronic respiratory problems), checklist for assessment of glutaraldehyde related work practice and pulmonary function tests. Results: Chronic cough was found in $52.0 \%$ of endoscopy nurses while asthma was only in $19.0 \%$ of nurse. Chronic respiratory problems increased in endoscopy nurses with increased work duration, poor work practices especially handling procedures and lack of training. All ventilatory lung function parameters of endoscopy nurses showed statistically significant decline with both increased work duration $\geq 15$ years and increased working hours $\geq 36$ hours per week. Majority of endoscopy nurses $30.0 \%$ had mild airflow obstruction. Conclusions: Highlighting the respiratory health problems and airway obstruction resulting from exposure to glutaraldehyde will raise the importance to use safer alternatives. Results will lead to implementing of training programs for proper cleaning and sterilization processes, also raising awareness and providing information about proper work practices of handling hazardous substances.
\end{abstract}

Keywords: Airway Obstruction, Endoscopy, Glutaraldehyde, Nurses, Occupational Exposure

\section{Introduction}

Nurses are exposed to different occupational risks in working environment including chemicals such as ethylene oxide (EtO) and glutaraldehyde (GA) which are commonly used for sterilization in various medical settings. Nurses and other health care workers are in danger of exposure while cleaning equipment and work surfaces. Although both of these chemicals are widely used for its effectiveness, they are associated with serious human health problems [1].

Glutaraldehyde is an aliphatic dialdehyde colorless liquid with a pungent odor. It is used in a wide range in medical field mainly for disinfection of medical instruments including endoscopes [2]. To prevent the spread of health-careassociated infections, all heat-sensitive endoscopes must be properly cleaned and subjected to high-level disinfection (HLD) after each use. For the past 40 years, GA (in $2-4 \%$ solution with water) has been the primary chemical used for HLD [3].

Occupational GA exposure mainly occurs through direct vapor inhalation and direct skin contact. Degree of occupational exposure to GA among nurses dealing with endoscopes depends on the frequency of sterilization, GA concentration, the endoscope rinsing method, room 
ventilation and availability of exhaust extraction vents [4].

Recent study done in Egypt reported symptoms related to GA including cough, rhinitis, skin symptoms and improved by applying a quality assurance program in endoscopy unit which also improved the safety of health personnel exposed to GA [5].

The shortage of nurses that may result from adverse health effects of exposure to Gluteraldehyde is a challenge for hospitals and a public concern. Nurses do innumerable things to guarantee the quality of services delivered to patients and also play an important role in hospitals quality improvement. Shortage impacts their capacity to provide nursing coverage for patient care and thus affect quality of services delivered to the community. Because of this shortage, nurse frequently need to work extended periods under exceptionally distressing conditions, which can cause injuries, fatigue and job dissatisfaction. Nurses facing these situations are prone to committing medical errors. As a result, the patient quality of care is affected leading to infections, increase hospital stay and increased death rates [6].

So because the study of GA exposure specifically at endoscopy units hasn't been done before in Zagazig University hospitals, and GA usage persists in many workplaces around Egypt, including Zagazig University Hospitals where occupational health knowledge among nurses and the regulation of dangerous chemicals are both suboptimal, this study was done to measure the frequency of respiratory health problems among endoscopy nurses exposed to GA, to assess endoscopy nurses work practice and to identify occupational risk factors associated with respiratory health problems.

\section{Materials and Methods}

\subsection{Study Settings and Sampling}

A comparative cross-sectional study was carried out in Zagazig University Hospitals at Endoscopy Units of different departments and in out-patient clinics during the period from January 2015 to February 2016.

The sample size of 126 nurses was calculated using EpiInfo (Epidemiological Information Package) software version 6.1 (Centers for Disease Control and Prevention, Atlanta, Ga). Nurses were distributed into: exposed group which consisted of 42 female nurses dealing with and exposed to GA during disinfection of endoscopes (19 nurses in Gastroenterology Unit, 4 nurses in Pediatric Unit, 9 nurses in Chest, Echo and Cardio-Thoracic surgery Units and 10 nurses in surgical Units), and non-exposed group which consisted of 84 female nurses working at outpatient clinics and not exposed to GA.

\subsubsection{Inclusion Criteria}

- Nurses working regularly and permanently (for more than 1 year) and exposed to GA during their current work at endoscopy units.

- Nurses working at outpatient clinics, never occupationally exposed to GA and comparable with the exposed group as regarding age, sex, income, educational level, residence, and smoking habits.

\subsubsection{Exclusion Criteria}

- Nurses working in endoscopy units less than one year.

- Previous history of respiratory diseases (bronchial asthma, chronic bronchitis, emphysema, pulmonary T.B, Pneumonia, chest injury or surgery) before joining the current job.

- History of acute exposure to gases, fumes or dust before joining the current job or in another job.

\subsubsection{Method of Allocation and Sample Selection}

By proportion allocation, the sample (42 nurses) was distributed among different types of Endoscopy Units according to their percentage in the total number of nurses as follows: 19 nurses in Gastroenterology Endoscopy Units, 10 nurses in Surgical Endoscopy Units, 9 nurses in Chest, Echo \& Cardio-Thoracic Surgery Endoscopy Units and 4 nurses in Pediatric Endoscopy Unit.

According to the list of nurses in each endoscopy unit and outpatient clinics, we selected the desired number by simple random sample.

\subsection{Pilot Study}

Was carried out on $10 \%$ of the sample selected randomly from endoscopy units in Zagazig University hospitals to test the questionnaire with the most appropriate terms and to estimate the time needed for data collection. It was also done to check the reliability and validity of the questionnaire. Validity was tested through opinions of three experts for language clarity, content, relevancy, ability to understand questions and time needed to answer. The reliability test was done for the internal consistency of the items by using the reliability coefficients (Cronbach's alpha $=0.8$ ) which were good and suitable for the questionnaire. Nurses included in the pilot study were 10 nurses and were enrolled in the study as no modifications were done in the tools of the study.

\subsection{Study Procedures}

A. Pre-constructed questionnaire sheet: All subjects were interviewed personally using a semi-structured questionnaire. The questionnaire for controls was identical to that for exposed nurses except for the omission of the questions related to glutaraldehyde, it includes:

i. Socio-demographic data: (age, sex, residence, educational level, marital status, and smoking habits)

ii. Occupational history: (duration of employment in current occupation, department, number of worked hours /week, training on GA use and usage of personal protective equipment PPE)

iii. Respiratory questionnaire: adopted from The Medical Research Council (MRC) questionnaire on respiratory symptoms [7].

B. Checklist for the assessment of GA-related work practices: adopted from OSHA [8] and it is used to check the following (transportation and storage, use and handling 
Procedures and disposal procedures)

\subsubsection{The Coding System}

Each item in the checklist for assessment of GA-related work practice is coded 1 if the answer was "Yes" and 0 if the answer was "No". We calculated total score for the checklist according to the following:

- Transportation and storage of Glutaraldehyde inside the unit $=3$ points.

- Usage and handling procedures of Glutaraldehyde = 18 points.

- Disposal procedures of Glutaraldehyde $=4$ points.

- Total performance: consists of all items in the checklist with total score $=25$ points.

- Work practice classified in each item into:

- Appropriate if the score $\geq 75 \%$ of the "Yes" answers of the total score.

- Poor if the score was $<75 \%$ of the "Yes" answers of the total score.

C. Computerized pulmonary function tests: All subjects in this study were subjected to pulmonary function tests at the end of work shift. A standard method for testing performance was used according to the American Thoracic Society recommendations [9] using portable spirometer (CONTEC SP10 Digital Spirometer Lung Breathing Diagnostic Vitalograph Spirometry).

\subsubsection{Classification and Severity Staging of Airflow Obstruction}

According to the American Thoracic Society (ATS)/European Respiratory Society (ERS) [10] using the severity of reductions in FEV1 by the following scheme:

- Mild: $70-79 \%$ of predicted

- Moderate: $60-69 \%$ of predicted

- Moderately severe: $50-59 \%$ of predicted

- Severe: $35-49 \%$ of predicted

- Very severe: Less than $35 \%$ of predicted.

\subsection{Data Collection}

The first visit was done to inform the heads of endoscopy units about the aim, objectives and methods of the study to ensure their commitment \& support and to take their permission to perform the study.

Then, the second visit was done to all endoscopy units to determine the total number of working nurses and asking about the suitable time for subsequent visits.

Ten subsequent visits included personal interviews to fill the questionnaires, time needed for filling the questionnaire from each nurse took about 10 minutes. Telephone follow-up was performed to gather additional information. Also, many subsequent visits were done to perform pulmonary function tests using portable spirometer at the end of work shift for all nurses interviewed before, it took about 5 minutes for each nurse after explaining and performing the procedure in front of them. Some nurses refused to perform pulmonary function tests (9 from exposed group and 11 from the control group) so the net number of nurses who completed the pulmonary function tests were 106 nurses.

\subsection{Statistical Analysis}

The collected data were computerized and statistically analyzed using SPSS program (Statistical Package for Social Science) version 16.0 (SPSS, Inc., an IBM Company, Chicago, IL, USA). Chi-squared test was used to calculate the difference between qualitative variables while t-test was used to calculate the difference between normally distributed quantitative variables and the Mann-Whitney test was used for not normally distributed quantitative variables. Pearson's correlation was done to test the association between two quantitative variables. A p-value of $<.05$ was considered as statistically significant.

\subsection{Ethical Approval}

The Institutional Review Board (IRB) of the faculty approved the study protocol (IRB \#1760). Permission from University Hospitals managing board was obtained. Ethical considerations and confidentiality were respected.

\subsection{Consent}

An informed consent was obtained from all participants in this study after explaining the benefits of the research. The nurses were informed about the aim of the study, and they were assured that the data would be used for scientific purposes only. The nurses were also given the right to refuse or participate in the study.

\section{Results}

Forty-two nurses from endoscopy units exposed to glutaraldehyde and 84 nurses from outpatient clinics in University hospitals engaged as control group participated in this study. Most of the nurses of both groups were $\geq 40$ years, married, graduated from the nursing institute, living in rural areas, working in their current job for $\geq 15$ years and for $\geq 36$ hours per week. All members of both exposed and control groups were females and non-smokers.

The majority of endoscopy nurses $97.6 \%$ use gloves, while $64.3 \%$ of them use aprons as a protective measure. During endoscopy sterilization, $42.9 \%$ and $28.6 \%$ of nurses use lab coats and surgical scrubs respectively, while $19.0 \%$ use surgical masks and $4.8 \%$ use face shields.

Assessment of endoscopy nurses practice, results showed that $67.5 \%$ of them had poor transportation \& storage, while $66.7 \%$ had poor usage \& handling procedures of GA. On the other hand, $78.6 \%$ of them had appropriate disposal procedures of GA. Overall total work practice was appropriate among only $35.7 \%$ of endoscopy nurses while it was poor among $64.3 \%$.

Results showed that there were high statistically significant differences between endoscopy nurses and controls regarding having chronic respiratory problems being higher among endoscopy nurses. The most prevalent chronic respiratory problem among them is chronic cough $52.0 \%$ 
compared to $14.3 \%$ of controls. Asthma was found in $19.0 \%$ of endoscopy nurses compared to $4.8 \%$ of controls (Table 1 ).

Table 1. Chronic respiratory problems in endoscopy nurses and their control group.

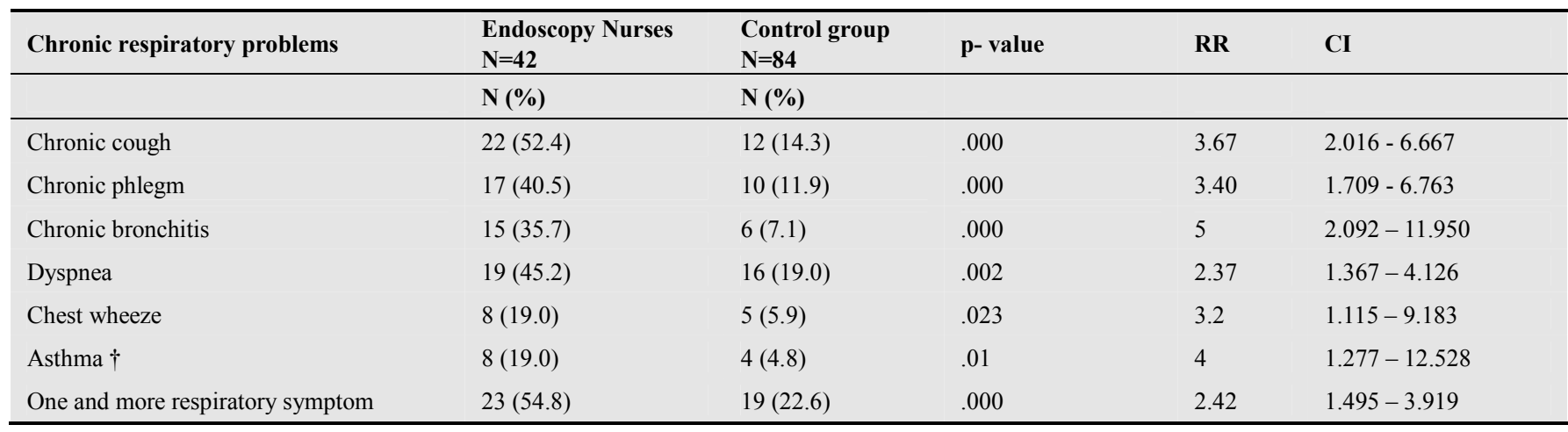

$\dagger$ work- related asthma

Statistically significant differences were found between increased duration of work, lack of training on GA use and having chronic respiratory problems $(\mathrm{P}<.001, \mathrm{P}<.05$ respectively). Also a high statistically significant difference was found between total poor work practice and having chronic respiratory problems $(\mathrm{P} \quad<.01)$ with special consideration for poor practice regarding usage $\&$ handling procedures of GA (Table 2).

Table 2. Difference between chronic respiratory problems and occupational characteristics, work practice among endoscopy nurses.

\begin{tabular}{|c|c|c|c|}
\hline \multirow[b]{2}{*}{ Variables } & \multicolumn{2}{|c|}{ Chronic respiratory problems } & \multirow[b]{2}{*}{ p-value } \\
\hline & $\begin{array}{l}(-v e)=19 \\
N(\%)\end{array}$ & $\begin{array}{l}(+v e)=23 \\
N(\%)\end{array}$ & \\
\hline \multicolumn{4}{|c|}{ Occupational characteristics: } \\
\hline \multicolumn{4}{|c|}{ Duration of work (years) in endoscopy units: } \\
\hline$<15$ years $(\mathrm{N}=16)$ & $13(43.7)$ & $3(56.3)$ & .000 \\
\hline$\geq 15$ years $(\mathrm{N}=26)$ & $6(46.2)$ & $20(53.8)$ & \\
\hline \multicolumn{4}{|c|}{ No of worked hours /week: } \\
\hline$<36$ hours $(\mathrm{N}=12)$ & $7(58.3)$ & $5(41.7)$ & .281 \\
\hline$\geq 36$ hours $(\mathrm{N}=30)$ & $12(40.0)$ & $18(60.0)$ & \\
\hline \multicolumn{4}{|l|}{ Training on GA use: } \\
\hline No $(\mathrm{N}=25)$ & $11(64.7)$ & $6(35.3)$ & .036 \\
\hline Yes $(\mathrm{N}=17)$ & $8(32.0)$ & $17(68.0)$ & \\
\hline \multicolumn{4}{|l|}{ Work practice: } \\
\hline \multicolumn{4}{|c|}{ Transportation and Storage of GA: } \\
\hline Poor $(\mathrm{N}=33)$ & $13(39.4)$ & $20(60.6)$ & .145 \\
\hline Appropriate $(\mathrm{N}=9)$ & $6(66.7)$ & $3(33.3)$ & \\
\hline \multicolumn{4}{|c|}{ Usage and handling Procedures: } \\
\hline Poor $(\mathrm{N}=28)$ & $8(28.6)$ & $20(71.4)$ & .002 \\
\hline Appropriate $(\mathrm{N}=14)$ & $11(78.6)$ & $3(21.4)$ & \\
\hline \multicolumn{4}{|l|}{ Disposal Procedures: } \\
\hline Poor $(\mathrm{N}=25)$ & $11(44.0)$ & $14(56.0)$ & \\
\hline Appropriate $(\mathrm{N}=17)$ & $8(47.1)$ & $9(52.9)$ & .845 \\
\hline \multicolumn{4}{|l|}{ Total work practice: } \\
\hline Poor $(\mathrm{N}=27)$ & $8(29.6)$ & $19(70.4)$ & \\
\hline Appropriate $(\mathrm{N}=15)$ & $11(73.3)$ & $4(26.7)$ & .006 \\
\hline
\end{tabular}

Note: GA= Glutaraldehyde

The ventilatory lung function measurements of endoscopy nurses were significantly lower than that of their control group (P $<.001)$ except for FVC (L) and FVC \% of predicted which showed no statistically significant difference between the two groups $(\mathrm{P}>.05)$ (Table 3$)$. 
Table 3. Difference between ventilatory lung function measurements among endoscopy nurses and their control group.

\begin{tabular}{|c|c|c|c|c|c|c|c|}
\hline Ventilatory lung function measurements & Endoscopy nurses $\mathbf{N}=\mathbf{3 3}$ & & & $\begin{array}{l}\text { Control group } \\
N=73\end{array}$ & & & P-value \\
\hline & mean \pm SD & & & mean \pm SD & & & \\
\hline $\mathrm{FVC}(\mathrm{L}) \dagger$ & $2.09 \pm 0.64$ & & & $2.07 \pm 0.41$ & & & .821 \\
\hline \multirow[t]{2}{*}{ FEV1(L) $\dagger$} & $1.53 \pm 0.52$ & & & $1.88 \pm 0.39$ & & & .000 \\
\hline & SE & Median & Range & SE & Median & Range & \\
\hline FEV1/FVC $\ddagger$ & 2.66 & 78.0 & 56.0 & 0.829 & 93.0 & 37.0 & .000 \\
\hline FEF $25 \%-75 \% \ddagger$ & 0.13 & 1.67 & 2.63 & 0.069 & 2.59 & 2.47 & .000 \\
\hline FEV1 \% Pred. $\ddagger$ & 3.09 & 46.0 & 75.0 & 1.473 & 61.0 & 49.0 & .001 \\
\hline
\end{tabular}

$\mathrm{SD}=$ standard deviation $\mathrm{SE}=$ standard error

$\dagger \mathrm{t}$-test was used

+ Mann-Whitney test was used

$\mathrm{FVC}=$ Forced Vital Capacity

$\mathrm{FEV}_{1}=$ Forced Expiratory Volume in 1 st second

$\mathrm{FEF}_{25-75}=$ Forced Expiratory Flow at $25-75 \%$ of forced vital capacity

$\%$ Pred. $=$ Percent Predicted

The degree of reduction in FEV1\% of predicted among endoscopy nurses was used to classify the severity of airflow obstruction, where $30.0 \%$ of endoscopy nurses had a mild obstruction, $15.0 \%$ had a moderate obstruction, $28.0 \%$ had moderately severe obstruction, $15.0 \%$ had severe obstruction and $12.0 \%$ had a very severe obstruction.

A negative correlations were found between some parameters of ventilatory lung functions (FEV1, FEV1/FVC, FEF $25 \%-75 \%$, FEV1\% Pred.) and the number of worked hours/week and duration of work in years. As work duration and the number of worked hours/week increased, all parameters of lung functions decreased except for FVC and FVC\% of Predicted. A strong negative correlation was found between FEF25\%-75\% and duration of work in years $(\mathrm{r}-0.6)$ (Table 4).

Table 4. Correlation between ventilatory lung function measurements and number of worked hours/week and duration of work among endoscopy nurses.

\begin{tabular}{lll}
\hline $\begin{array}{l}\text { Ventilatory lung function } \\
\text { measurements }\end{array}$ & $\begin{array}{l}\text { Number of worked } \\
\text { hours /week }\end{array}$ & $\begin{array}{l}\text { Duration of } \\
\text { work (years) }\end{array}$ \\
\hline & $(\mathrm{r})$ & $(\mathrm{r})$ \\
FVC(L) & -0.05 & -0.04 \\
FEV1(L) & -0.41 & -0.31 \\
FEV1/FVC & -0.44 & -0.39 \\
FEF25\%-75\% & -0.52 & -0.60 \\
FVC\%PRED & -0.06 & -0.08 \\
FEV1\%PRED & -0.38 & -0.40 \\
\hline
\end{tabular}

$\mathrm{FVC}=$ Forced Vital Capacity

$\mathrm{FEV}_{1}=$ Forced Expiratory Volume in 1 st second

$\mathrm{FEF}_{25-75}=$ Forced Expiratory Flow at $25-75 \%$ of forced vital capacity

$\%$ Pred. $=$ Percent Predicted

\section{Discussion}

Glutaraldehyde enables rapid disinfection and is economical so in developing countries, its usage persists in spite of its well-known health hazards. Using goggles and masks or respirators in disinfection procedures is important, however, the majority of endoscopy nurses used latex gloves $97.6 \%$ while $19.0 \%$ of them used surgical masks, goggles were not used at all. This agrees with Al-Batanony and ElShafie [11] who reported that all endoscopy nurses in their study used gloves but no masks during working, also Nayebzadeh [12] reported that latex gloves were used by the majority of nurse to protect hands from direct skin contact with GA, while only $15.0 \%$ of them used face protection. This indicates that reluctance in using personal PPE in our study contributed to the high prevalence of occupational respiratory problems which can be attributed to unavailability of PPE and lack of knowledge about its importance.

Assessment of GA-related work practice showed that the majority of endoscopy nurses had poor transportation \& storage GA, this was mainly due to improper fitting of containers cover during transporting GA solution leading to its dripping. While storage of unused glutaraldehyde solutions was noticed to be in tightly covered containers in a cool, secured, and properly labeled area but lacked proper ventilation.

Poor usage \& handling procedures noticed by the absence of proper PPE (as splash-proof goggles, respirators, and full face shields) with the availability of only latex gloves, ordinary lab coat or gown. Moreover, in most places where GA is used, no special cabinet or a dedicated room available for reprocessing of endoscopes which make exposure levels higher. Besides, presence of manual reprocessing techniques which still used in all endoscopy units except hematology unit increases the possibility of high exposure levels to GA. Only small percentage of nurses $21.4 \%$ had poor disposal practice which was mainly due to negligence in the immediate disposal of gloves, tissues, contaminated linen and towels after use in a specially designed containers.

Results showed that all chronic respiratory problems were more prevalent in endoscopy nurses than in control group, where the most prevalent chronic respiratory symptom was chronic cough $52.0 \%$ followed by dyspnea $45.2 \%$, workrelated asthma was also reported by $19.0 \%$ of endoscopy nurses. This was in agreement with an Egyptian study which reported that the most prevalent respiratory symptoms among 
endoscopy nurses were chronic cough $13.3 \%$ followed by chest wheeze $10.0 \%$ and chronic bronchitis \& dyspnea $6.7 \%$ with high significant differences between them and their control group [10]. Also, Katagiri et al. [13] showed that there was significant prevalence of chronic cough $29.0 \%$, chronic phlegm $12.9 \%$, asthma $6.4 \%$, and dyspnea $3.2 \%$ in endoscope disinfection workers, compared with their controls.

Our results are also supported by Arif and Delclos [14] who proved that workplace exposure to cleaning, disinfecting - related chemicals were associated with the development of work-related asthma symptoms, work-exacerbated asthma and/or occupational asthma, especially among female healthcare professionals.

It was found in this study that increased years of working in endoscopy units for $\geq 15$ years was associated with increasing prevalence of chronic respiratory problems. Results were consistent with Ong et al. [15] who found a case presented with adult onset asthma 2 years after daily exposure to GA. This can be explained by RomanoWoodward [16] who found that GA vapor may irritate the respiratory tract, resulting in coughing, wheezing, chest tightness, and eventually asthma which usually occurs after a latent period which may vary from few weeks to twenty years.

Also, results showed that chronic respiratory problems were significantly higher among nurses who didn't have training compared to those who had $(\mathrm{P}<.05)$. Endoscopy nurses in this study who received training on GA use are only $40.5 \%$ of the nurses, which means that more than $50.0 \%$ didn't have training courses which exposed them to GA hazards during usage and handling of GA. This agrees with a study performed by Gado et al. [17] who reported improvement in health and safety of personnel exposed to disinfectants which were obtained through providing training, education and encouraging continual improvement in workplace safety and health.

Nurses with poor total work practice with special consideration to poor usage \& handling procedures of GA had statistically higher chronic respiratory problems $(\mathrm{P}<.01)$. This agrees with Katagiri et al. [13] who reported that disuse of masks and goggles may lead to high levels of respiratory problems. Besides, Nayebzadeh [12] documented that poor usage $\&$ handling of GA generate splashes, droplets, and vapor release that harm the eye, skin, mucous membranes, and respiratory tract.

Ventilatory lung function measurements of endoscopy nurses were significantly lower than that of their control group. Similarly, Al-Batanony and El-Shafie [11] reported a significant decline of the mean value of lung function parameters among endoscopy nurses exposed to GA than non-exposed group.

Airway obstruction is the most common cause of the reduction in FEV1 and FEV1/FVC ratio remains the most commonly used parameter for diagnosis [18], the severity of airflow obstruction was mild among $30.0 \%$ of endoscopy nurses while only $12.0 \%$ had very severe obstruction. This can be explained by McCarthy [19] study who noticed that the unbalanced reduction in the FEV1 as compared to the FVC is a sign of obstructive lung diseases such as asthma, acute and chronic bronchitis, emphysema, bronchiolitis, and bronchiectasis. Also, in a case study by Copeland and Nugent they reported multiple spirometric tests during evaluation which showed variable results glutaraldehyde-induced occupational asthma including restrictive pattern and obstructive pattern [20].

The study found a significant negative correlation between some lung functions parameters, the number of worked hours/week and duration of work in years. This was confirmed before by other studies in Egypt and Pakistan [11, 21] which found a correlation between respiratory symptoms, work duration and lung functions and found that respiratory symptoms such as cough, phlegm, wheeze and shortness of breath and increased work duration significantly correlated with diminished lung function and this was noticed for all lung volumes. These findings indicated that respiratory symptoms and duration of work with GA were the important predictor of decreased lung function.

Limitation of the study included lack of cooperation either due to refusal of nurses to participate for fear of cross infection (in spite of explaining that everyone has his own mouthpiece which is disposable and not re-used by another one) or refusal to go to the Chest department for measuring lung functions where there is a fixed spirometer, also In our study, environmental measurements of GA were not done due to lack of specific instruments needed for this purpose.

\section{Conclusions}

From this study, we concluded that exposure to Glutaraldehyde put endoscopy nurses at risk of having respiratory health problems and airway obstruction especially in nurses with poor work practices and increased work duration which were reflected on increasing time and dose of exposure to Glutaraldehyde. Hospitals showed a defect in training system as no special training on Glutaraldehyde usage were given to all nurses. Training is the key element to ensure proper work practices and therefore protect nurses from Glutaraldehyde hazards.

So based on this study and taking in consideration that nurses' health is a public concern we recommend regular training programs on handling hazardous substances with a focus on GA. Written procedures for safe working practices should be provided for all nurses. Periodic environmental monitoring of atmospheric GA concentration in the workplace is mandatory to detect any abnormal levels which require effective control measures. We strongly recommend substitution of GA with peracetic acid, however, due to the price difference as the cost of one bottle of glutaraldehyde $2 \%$ is 70 L.E and peracetic acid is 213 L.E., we recommend performing of other types of epidemiological studies that dose-relate various glutaraldehyde health problems with the intensity of exposure in order to push the higher authorities to take a serious action concerning this issue. 


\section{References}

[1] Trinkoff AM, Geiger-Brown JM, Caruso CC, Lipscomb JA, Johantgen M, Nelson AL, Sattler BA, Selby VL. Personal Safety for Nurses. In: Hughes RG, editor. Patient Safety and Quality: An Evidence-Based Handbook for Nurses [Internet]. Rockville (MD): Agency for Healthcare Research and Quality (US). Chapter 39. P.473-508; 2008 Apr [cited 2015 Jan 10]. Available from:

http://www.ncbi.nlm.nih.gov/books/NBK2661/

[2] Takigawa T, Endo Y. Effects of glutaraldehyde exposure on human health. J Occup Health 2006; 48:75-87. http://doi.org/10.1539/joh.48.75

[3] Rideout K, Teschke K, Dimich-Ward H, Kennedy SM. Considering risks to healthcare workers from glutaraldehyde alternatives in high-level disinfection. Journal of Hospital Infection 2005; 59:4-11. http://doi.org/10.1016/j.jhin.2004.07.003

[4] Smith DR, Wang RS. Glutaraldehyde exposures and its occupational impact in the health care environment. Environ Health Prev Med 2006; 11:3-10. http://doi.org/10.1007/BF02898201

[5] Gado A, Ebeid B, Abdelmohsen A, Axon A. Improving safety of personnel exposed to disinfectants by introducing an Endoscopy Quality Assurance Program. Alexandria Journal of Medicine 2014; 50:7-12. http://doi.org/10.1016/j.ajme.2013.03.001

[6] American Association of Colleges of Nursing. Nursing Shortage Fact Sheet [Internet]. 2014 [updated 2014 April 24; cited 2016 Sept 22]. Available from: http://www.aacn.nche.edu/mediarelations/FacultyShortageFS.pdf

[7] Cotes JE, Chinn DJ. MRC questionnaire (MRCQ) on respiratory symptoms. Occupational Medicine 2007; 57:388. http://dx.doi.org/10.1093/occmed/kqm051

[8] OSHA (Occupational Safety and Health Administration). Best practices for the safe use of glutaraldehyde in health care [Internet]. OSHA 3258-3308.N, 2006 [cited 2015 March 15]. Available from: www.osha.gov/Publications/glutaraldehyde.pdf

[9] Miller MR, Hankinson J, Brusasco V, Burgos F, Casaburi R, Coates A, et al. Standardisation of spirometry. Series "ATS/ERS Task force: Standardisation of lung function testing". Eur Respir J [Internet] 2005; 26:319-38. Available from:

https://www.thoracic.org/statements/resources/pfet/PFT2.pdf

[10] Gildea TR, McCarthy K. Pulmonary function testing. In
Cleveland clinic: current clinical medicine, 2010. [cited 2015 April 3]. Available from: http://www.clevelandclinicmeded.com/medicalpubs/diseasem anagement/pulmonary/pulmonary-function-testing/

[11] Al-Batanony MA, El-Shafie MK. Evaluation of Occupational Exposure to Glutaraldehyde among Endoscopy Nursing staff in Menoufiya University Hospital. Egyptian Journal of Occupational Medicine 2007; 31:75-85

[12] Nayebzadeh A. The effect of work practices on personal exposure to glutaraldehyde among health care workers. Industrial Health 2007; 45:289-95. http://doi.org/10.2486/indhealth.45.289

[13] Katagiri H, Suzuki T, Aizawa Y, Kadowaki T. Indoor Glutaraldehyde Levels in the Endoscope Disinfecting Room and Subjective Symptoms among Workers. Industrial Health 2006; 44:225-9. http://doi.org/10.2486/indhealth.44.225

[14] Arif AA, Delclos GL. Association between cleaning-related chemicals and work-related asthma and asthma symptoms among healthcare professionals. Occup Environ Med 2012; 69:35-40. http://dx.doi.org/10.1136/oem.2011.064865

[15] Ong TH, Tan KL, Lee HS, Eng P. A case report of occupational asthma due to gluteraldehyde exposure. AnnalsAcademy of Medicine Singapore 2004; 33:275-8.

[16] Romano-Woodward D. Safe use of glutaraldehyde. Nursing Standard 2000; 14:47-51.

http://dx.doi.org/10.7748/ns2000.04.14.32.47.c2825

[17] Gado A, Ebeid B, Abdelmohsen A and Axon A. Improving safety of personnel exposed to disinfectants by introducing an Endoscopy Quality Assurance Program. Alexandria Journal of Medicine 2014; 50(1):7-12. http://dx.doi.org/10.1016/j.ajme.2013.03.001

[18] Athanazio R. Airway disease: similarities and differences between asthma, COPD and bronchiectasis. Clinics 2012, 67(11):1335-1343.

http://dx.doi.org/10.6061/clinics/2012(11)19

[19] McCarthy K. Pulmonary Function Testing. Medscape [Internet], 2015 [updated 2015 Feb 18; cited 2015 April 8]. Available from: http://emedicine.medscape.com/article/303239-overview

[20] Copeland S and Nugent K. Persistent and unusual respiratory findings after prolonged glutaraldehyde exposure. Int J Occup Environ Med 2015; 6:177-183

[21] Abbasi IN, Ahsan A, Nafees AA. Correlation of respiratory symptoms and spirometric lung patterns in a rural community setting, Sindh, Pakistan: a cross sectional survey. BMC Pulmonary Medicine 2012; 12:81. http://dx.doi.org/10.1186/1471-2466-12-81 